\begin{tabular}{|c|l|}
\hline Title & $\begin{array}{l}\text { Photochemical fine tuning of luminescent color of cadmium selenide nanoparticles : fabricating a single source } \\
\text { multicolor luminophore }\end{array}$ \\
\hline Author(s) & $\begin{array}{l}\text { Torimoto, T sukasa; Murakami, Shinya; Sakuraoka, Miwa; I wasaki, Kentaro; Okazaki, Kenichi; Shibay ama, Tamaki; } \\
\text { Ohtani, Bunsho }\end{array}$ \\
\hline Citation & $\begin{array}{l}\text { Journal of physical chemistry. B, 110(27), 13314 13318 } \\
\text { https://doi.org/10.1021/p062645c }\end{array}$ \\
\hline Issue Date & 2006-07-13 \\
\hline Doc URL & http://hdl.handle.net/2115/52785 \\
\hline Type & article \\
\hline File Information & jp062645c.pdf \\
\hline
\end{tabular}

Instructions for use 


\title{
Photochemical Fine-Tuning of Luminescent Color of Cadmium Selenide Nanoparticles: Fabricating a Single-Source Multicolor Luminophore
}

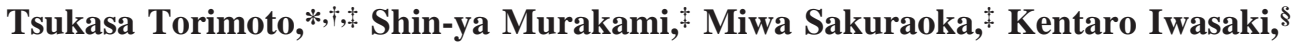 \\ Ken-ichi Okazaki, Tamaki Shibayama," and Bunsho Ohtani ${ }^{\S, \perp}$ \\ Department of Crystalline Materials Science, Graduate School of Engineering, Nagoya University, Chikusa-ku, \\ Nagoya 464-8603, Japan, "Light and Control" PRESTO, JST, 4-1-8 Honcho, Kawaguchi 332-0012, Japan, \\ Graduate School of Environmental Earth Science, Hokkaido University, Sapporo 060-0810, Japan, Center for \\ Advanced Research of Energy Conversion Materials, Hokkaido University, Sapporo 060-8628, Japan, and \\ Catalysis Research Center, Hokkaido University, Sapporo 001-0021, Japan
}

Received: April 30, 2006; In Final Form: June 9, 2006

\begin{abstract}
Size-selective photoetching was applied to silica-coated cadmium selenide $\left(\mathrm{SiO}_{2} / \mathrm{CdSe}\right)$ nanoparticles to precisely control their photoluminescence properties. The absorption spectra of CdSe was blue-shifted by irradiation of monochromatic light, and finally, the absorption onset agreed with the wavelength of irradiation light, indicating that CdSe particles were photoetched to smaller ones until the irradiated photons were not absorbed by the photoetched particles and that the $\mathrm{SiO}_{2}$ shell layer surrounding the CdSe core prevented coalescence between the photoetched particles. Although as-prepared $\mathrm{SiO}_{2} / \mathrm{CdSe}$ did not exhibit photoluminescence, the application of size-selective photoetching to $\mathrm{SiO}_{2} / \mathrm{CdSe}$ resulted in the development of the band gap emission, with the degree being enhanced with progress of the photoetching. The peak wavelength of photoluminescence decreased with a decrease in the wavelength used for the photoetching, so that the luminescence color could be tuned between red and blue. Partial photoetching of $\mathrm{SiO}_{2} / \mathrm{CdSe}_{\text {nanoparticle }}$ films produced intense band gap emission of $\mathrm{CdSe}$ at the photoetched area, while the remainder of the $\mathrm{SiO}_{2} /$ $\mathrm{CdSe}$ films did not exhibit detectable photoluminescence, resulting in the formation of a clear photoluminescence image under UV irradiation. This technique makes it possible to produce a multicolored photoluminescence image by irradiation with monochromatic lights having various wavelengths using a single source material.
\end{abstract}

\section{Introduction}

Size-quantized semiconductor nanoparticles have been promising materials for applications such as multicolored fluorescent markers for biological analysis and optoelectronics devices. ${ }^{1-10}$ Cadmium selenide (CdSe) nanoparticles have been intensively investigated because their band gap emission can be tuned in the whole visible region depending on their particle size. ${ }^{1,4,6}$ Various methods for the synthesis of CdSe nanoparticles have been reported, and it has been shown that particle size was varied by reaction conditions, such as reaction temperature and time. In most cases, crystal growth in hot organic solvents must be monitored during the progression of the reaction, and difficult techniques have therefore been required for controlling the size of nanoparticles formed. . $^{2,4,6,11,12}$

* Corresponding address: Prof. Tsukasa Torimoto, Department of Crystalline Materials Science, Graduate School of Engineering, Nagoya University, Chikusa-ku, Nagoya 464-8603, Japan. Phone: +81-52-7894614. Fax: +81-52-789-5299. E-mail: torimoto@apchem.nagoya-u.ac.jp.

Nagoya University.

$\doteqdot$ JST.

$\S$ Graduate School of Environmental Earth Science, Hokkaido University.

"Center for Advanced Research of Energy Conversion Materials, Hokkaido University.

${ }^{\perp}$ Catalysis Research Center, Hokkaido University.
We have reported the use of the size-selective photoetching technique for preparing monodisperse cadmium sulfide (CdS) nanoparticles in the size quantization regime, in which the particle size is simply determined by the wavelength of monochromatic light and can be controlled within the range $3.7-1.7 \mathrm{~nm}$ by changing the wavelength of irradiation light within the range $514-365 \mathrm{~nm} .{ }^{13-17}$ It was also shown that the photoluminescence of photoetched CdS nanoparticles could be controlled in the region of blue light: the intense band gap emission was blue-shifted from 479 to $456 \mathrm{~nm}$ with a decrease in the wavelength used for the photoetching from 488 to 450 $\mathrm{nm} .{ }^{13,17}$ On the other hand, it has recently been reported that postpreparative photoirradiation remarkably enhanced the photoluminescence intensity with a slight blue shift of the emission peak probably due to the changes in the surface conditions with partial photooxidation of CdSe particles. ${ }^{18-22}$ However, to the best of our knowledge, band gap emission at a desired position has not been obtained by using any postpreparative strategies. If the size-selective photoetching technique is applied for CdSe nanoparticles that have a smaller band gap than that of CdS nanoparticles, their photoluminescence properties can be precisely adjusted in the whole wavelength range of visible light simply by choosing the wavelength used for the photoetching, 
but this has not been attempted. In this paper, we report the fine-tuning of photoluminescence color of $\mathrm{CdSe}$ nanoparticles by size-selective photoetching. The photoluminescence was considerably enhanced with the photoetching of CdSe and blueshifted with a decrease in the wavelength used for the photoetching.

\section{Experimental Section}

CdSe nanoparticles were prepared in trioctylphosphine oxide (TOPO)/trioctylphosphine (TOP) mixed solvent with slight modification of previously reported procedures. ${ }^{4}$ A mixture of TOPO $(5.0 \mathrm{~g})$ and cadmium acetate $(0.50 \mathrm{mmol})$ was put in a reaction vessel and heated to 150 or $175{ }^{\circ} \mathrm{C}$ under an argon atmosphere, and then, a $2.0 \mathrm{~cm}^{3}$ trioctylphosphine (TOP) solution containing $0.63 \mathrm{mmol}$ selenium was added, followed by stirring for $1 \mathrm{~h}$. After cooling to room temperature, the reaction mixture $(0.50 \mathrm{~g})$ was dissolved in butanol. By the addition of methanol to the solution, the wet precipitate of TOPO-modified CdSe nanoparticles was obtained. This was dissolved in $50 \mathrm{~mm}^{3}$ of 3-mercaptopropyltrimethoxysilane (MPTS) to modify the surface of CdSe nanoparticles (MPTS/ $\mathrm{CdSe}$ ), where thiol groups of MPTS molecules were strongly bound to $\mathrm{Cd}^{2+}$ sites of nanoparticles. ${ }^{15}$ A colloidal solution of water-soluble $\mathrm{SiO}_{2}$-coated CdSe nanoparticles $\left(\mathrm{SiO}_{2} / \mathrm{CdSe}(\mathrm{col})\right)$ was prepared from MPTS/CdSe by using the same method as that reported by Alivisatos and co-workers, ${ }^{5}$ with the outermost layer being prepared through the condensation of surface hydroxyl groups on the $\mathrm{SiO}_{2}$ shell with (trihydroxysilyl)propyl methylphosphonate (TSPP) and hydrolysis (Figure S1a in the Supporting Information). The resulting nanoparticles were dissolved in an aqueous solution and purified by dialysis. The size of $\mathrm{SiO}_{2} / \mathrm{CdSe}$ (col) was investigated by an atomic force microscope (AFM) (Digital Instruments, Nanoscope IIIa) in a tapping mode. The AFM samples were prepared by spreading a small portion of $\mathrm{SiO}_{2} / \mathrm{CdSe}$ (col) solution on a freshly cleaved mica surface and drying.

Immobilization of $\mathrm{SiO}_{2} / \mathrm{CdSe}$ nanoparticle films on a glass substrate $\left(\mathrm{SiO}_{2} / \mathrm{CdSe}\right.$ (film)) was performed by the following procedure. MPTS/CdSe nanoparticles were dissolved in a methanol solution $\left(120 \mathrm{~cm}^{3}\right)$ containing $0.3 \mathrm{~g}$ of tetramethylammonium hydroxide and stirred for $1 \mathrm{~h}$. After addition of acetic acid $\left(0.60 \mathrm{~cm}^{3}\right)$, the solution was poured into a vessel in which a glass substrate $\left(1.2 \times 1.2 \mathrm{~cm}^{2}\right)$ was horizontally placed on the bottom. The solution was left standing for several days until the $\mathrm{SiO}_{2} / \mathrm{CdSe}$ particles had settled. The substrate was carefully taken out from the vessel without destruction of the $\mathrm{SiO}_{2} / \mathrm{CdSe}$ layer, followed by drying and heating $\left(110{ }^{\circ} \mathrm{C}\right)$ under vacuum to secure a $\mathrm{SiO}_{2} / \mathrm{CdSe}$ film with cross-linking between particles via $\mathrm{Si}-\mathrm{O}-\mathrm{Si}$ networks (Figure $\mathrm{S} 1 \mathrm{~b}$ ). The film thickness was determined to $2.4 \mu \mathrm{m}$ by the observation of a scanning electron microscope. The density of CdSe immobilized in the film was

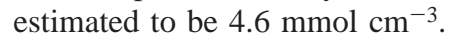

Size-selective photoetching was performed using an Nd:YAG laser equipped with an optical parametric oscillator (Continuum, Surelite II-OPO system) as a light source. The laser light with a desired wavelength was irradiated to an oxygen-saturated aqueous solution containing $\mathrm{SiO}_{2} / \mathrm{CdSe}$ (col) or a film of $\mathrm{SiO}_{2} /$ $\mathrm{CdSe}$ (film) immersed in oxygen-saturated water.

\section{Results and Discussion}

The increase in reaction temperature at crystal growth induced a red shift of absorption spectra of TOPO-modified CdSe nanoparticles, that is, an increase in the size of CdSe; nanoparticles prepared at 150 and $175^{\circ} \mathrm{C}$ exhibited absorption onset
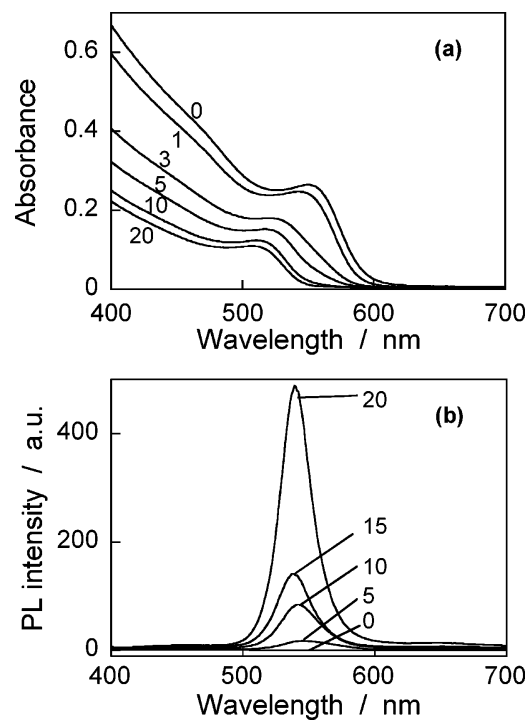

Figure 1. Changes in the absorption (a) and photoluminescence (PL) spectra (b) of $\mathrm{SiO}_{2} / \mathrm{CdSe}$ (col) nanoparticles during size-selective photoetching at $560 \mathrm{~nm}$. The excitation wavelength in PL measurement was $350 \mathrm{~nm}$. Irradiation times in units of hours are indicated in both figures. Original $\mathrm{CdSe}$ particles prepared at $150{ }^{\circ} \mathrm{C}$ were used.

(exciton peak) at 610 (552) and $670(618) \mathrm{nm}$, respectively. Thus, size-selective photoetching was performed for original $\mathrm{CdSe}$ nanoparticles prepared at $150{ }^{\circ} \mathrm{C}$ using monochromatic light with a wavelength shorter than $590 \mathrm{~nm}$, and those prepared at $175{ }^{\circ} \mathrm{C}$ were photoetched at a wavelength shorter than 630 $\mathrm{nm}$.

Figure 1a shows the changes in the absorption spectra of $\mathrm{SiO}_{2} /$ $\mathrm{CdSe}$ (col) with irradiation of monochromatic light at $560 \mathrm{~nm}$. The spectrum of original $\mathrm{SiO}_{2} / \mathrm{CdSe}$ (col) exhibited absorption onset and exciton peak with wavelengths of 610 and $553 \mathrm{~nm}$, respectively, which agreed well with those of TOPO-modified $\mathrm{CdSe}$ nanoparticles without surface coating. This indicated that almost no changes in the size, as well as in the size distribution, of nanoparticles occurred during the process of $\mathrm{SiO}_{2}$-shell formation onto CdSe. AFM observations revealed that the average size of the original $\mathrm{SiO}_{2} / \mathrm{CdSe}(\mathrm{col})$ was determined to be about $8.3 \mathrm{~nm}$ with a standard deviation of $2.2 \mathrm{~nm}$, by measuring the height of individual particles. On the other hand, the CdSe core size could be estimated to $3.1 \mathrm{~nm}$ from the wavelength of the exciton peak from the reported relation between exciton peak position and CdSe size. ${ }^{23}$ Considering that the upper most layer, i.e., the $\mathrm{SiO}_{2}$ shell layer, was reflected in the AFM images, the thickness of the $\mathrm{SiO}_{2}$ shell layer can be estimated to about $2.6 \mathrm{~nm}$ as half the difference between the size of $\mathrm{SiO}_{2} / \mathrm{CdSe}$ and that of $\mathrm{CdSe}$ core.

A gradual blue shift of the absorption spectra was observed with irradiation, and finally, the absorption onset agreed well with the wavelength of the irradiation light. Further irradiation beyond $20 \mathrm{~h}$ did not induce an appreciable shift of the absorption spectra. In the case in which the irradiation was performed in an Ar atmosphere, the blue shift of the absorption spectra was not observed. It is well-known that cadmium chalcogenide semiconductor particles are anodically corroded by irradiation in the presence of $\mathrm{O}_{2}$ as an electron scavenger. Though the photooxidation product of $\mathrm{CdSe}$ nanoparticles has not been analyzed in the present experiment, the previous investigation has confirmed the formation of $\mathrm{SeO}_{2}$ as a oxidation product. ${ }^{24}$ Furthermore, it has been reported that the photoirradiation of an aqueous solution containing $\mathrm{CdSe}$ nanoparticles caused the liberation of $\mathrm{Cd}^{2+}$ ions in the solution along with the photo- 
oxidation of CdSe. Thus, the net reaction is reasonably assumed to be eq $1 .^{25,26}$ The results shown in Figure 1a indicated that

$$
\mathrm{CdSe}+{ }^{3} / 2 \mathrm{O}_{2}+2 \mathrm{H}^{+} \stackrel{h v}{\longrightarrow} \mathrm{Cd}^{2+}+\mathrm{SeO}_{2}+\mathrm{H}_{2} \mathrm{O}
$$

size-selective photoetching of CdSe was successfully performed, and the large $\mathrm{CdSe}$ particles were photoetched to smaller ones until the irradiated photons were not absorbed by the particles due to an increase in the energy gap along with a decrease in the particle size (i.e., size quantization effect). The wavelength of the exciton peak was blue-shifted to $516 \mathrm{~nm}$ from that of original particles, $553 \mathrm{~nm}$, with photoetching at $560 \mathrm{~nm}$, corresponding to a decrease in CdSe size from 3.1 to $2.5 \mathrm{~nm}$ that was estimated from the reported relation between exciton peak position and $\mathrm{CdSe}$ size. ${ }^{23}$ Photoetched $\mathrm{SiO}_{2} / \mathrm{CdSe}$ (col) was stable without sedimentation for at least several weeks when stored in the dark. This fact indicated that the $\mathrm{SiO}_{2}$ shell layer surrounding the $\mathrm{CdSe}$ core prevented coalescence between the photoetched CdSe particles. It should be noted that, even when CdSe nanoparticles prepared at different temperatures, i.e., of different sizes, were used, photoetching with monochromatic light produced $\mathrm{CdSe}$ nanoparticles having an exciton peak at almost the same position, i.e., of the same size. It has been reported for $\mathrm{SiO}_{2}$-coated $\mathrm{CdS}$ in our previous paper ${ }^{27}$ that the increase in the shell thickness retarded the photoetching rate of $\mathrm{CdS}$ core owing to the lowered probability of the scavenging of the photoexcited electrons in $\mathrm{CdS}$ core with $\mathrm{O}_{2}$. Though there were no experimental results obtained in the present study, similar dependence of the photoetching rate of $\mathrm{CdSe}$ core on the shell thickness could be expected for $\mathrm{SiO}_{2} / \mathrm{CdSe}$ particles. Thus, it was suggested that the large shell thickness of the present $\mathrm{SiO}_{2} / \mathrm{CdSe}$ (col) (ca. $2.6 \mathrm{~nm}$ ) gave the slow photoetching rate of CdSe core as observed in Figure 1a.

Photoluminescence of TOPO-modified CdSe nanoparticles assigned to their band gap emission at $600 \mathrm{~nm}$ (not shown) was almost completely quenched in $\mathrm{SiO}_{2} / \mathrm{CdSe}$ before photoetching, suggesting that radiationless recombination sites were produced on the CdSe surface by modification with a thiol group of MPTS used for the preparation of the $\mathrm{SiO}_{2}$ shell. Similar phenomena have been reported; replacement of TOPO by alkanethiol compounds induced annihilation of photoluminescence of $\mathrm{CdSe}$ nanoparticles. ${ }^{21,28,29}$ On the other hand, size-selective photoetching of $\mathrm{SiO}_{2} / \mathrm{CdSe}$ resulted in the recovery of the band gap emission, the intensity of which was considerably developed by the progress of photoetching as shown in Figure 1b. Along with the blue shift of the absorption spectra, the emission peak was blue-shifted with narrowing its width (Figure S2 in the Supporting Information), but the degree of the peak shift was smaller than that of exciton absorption peak. This could be explained by the difference in the contribution of the photoetched CdSe particles to the spectra; the photoluminescence spectra were considerably affected by the size distribution of highly luminescent particles of photoetched CdSe, while the absorption spectra were simply represented by the sum of the absorption properties of the whole particles, irrespective of the luminescent properties of individual particles. The photoluminescence intensity of photoetched particles was not remarkably changed for several weeks when the solution was stored in the dark under an Ar atmosphere. This is in marked contrast to the case of alkanethiol-modified CdSe reported by Peng and coworkers, ${ }^{21}$ for which the subsequent treatments such as chemical oxidation and photooxidation of thiol-modified CdSe did not result in recovery of noticeable photoluminescence for nanocrystals. It has been reported in our previous paper ${ }^{15,27}$ that the
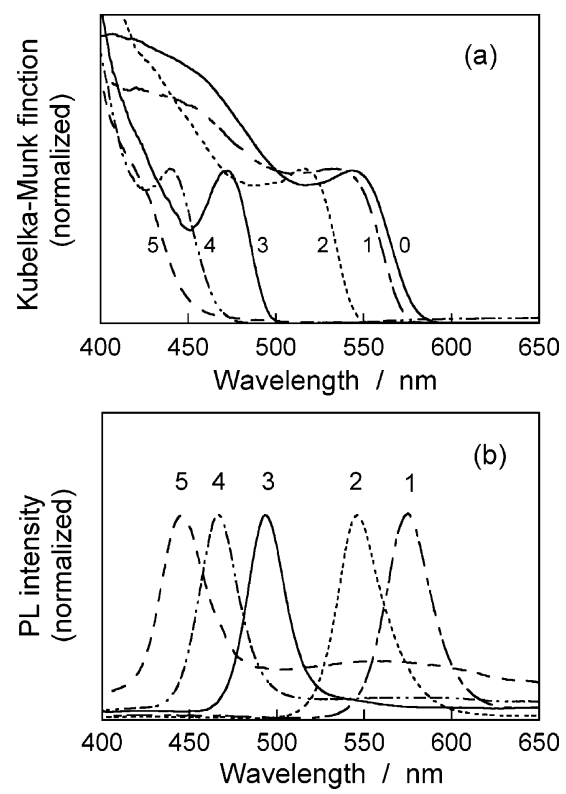

Figure 2. Diffuse reflectance spectra (a) and photoluminescence spectra (b) of $\mathrm{SiO}_{2} / \mathrm{CdSe}$ (film) nanoparticle films photoetched at various wavelengths: non-photoetched film (0) and photoetched films prepared by irradiation at 590 (1), 560 (2), 514 (3), 488 (4), and $460 \mathrm{~nm}$ (5). The excitation wavelength in PL measurement was $350 \mathrm{~nm}$. Original CdSe particles were prepared at $150{ }^{\circ} \mathrm{C}$.

size-selective photoetching of $\mathrm{SiO}_{2}$-coated $\mathrm{CdS}$ particles caused the selective decrease of $\mathrm{CdS}$ core size without any shrinkage of $\mathrm{SiO}_{2}$ shell structure and produced the void space between the core and the shell (jingle bell structure), resulting in the formation of a bare $\mathrm{CdS}$ surface within the $\mathrm{SiO}_{2}$ shell. Although a transmission electron microscope observation of the present $\mathrm{SiO}_{2} / \mathrm{CdSe}$ could not give clear images of void space between the core and the shell probably because of both the large shell thickness and the superimposition of the images of $\mathrm{SiO}_{2}$ shell and amorphous carbon layer, it could be assumed that the decrease of the CdSe core by the photoetching made a void space between the $\mathrm{CdSe}$ core and the $\mathrm{SiO}_{2}$ shell with a bare surface of CdSe core, as well as in the case of CdS. This situation would cause the photooxidative desorption of thiol groups of MPTS from the particle surface and decrease the amount of recombination sites produced during the modification procedure of CdSe surface, resulting in the enhancement of the photoluminescence of the photoetched CdSe core.

Size-selective photoetching is also applicable to $\mathrm{SiO}_{2} / \mathrm{CdSe}$ nanoparticles immobilized on a glass substrate. Figure 2 shows the diffuse reflectance spectra and photoluminescence spectra of $\mathrm{SiO}_{2} / \mathrm{CdSe}$ (film) after photoetching with monochromatic light having various wavelengths. Irradiation at a shorter wavelength caused a larger blue shift of the spectra, and each absorption onset in Figure 2a agreed well with the wavelength of monochromatic irradiation, indicating that all of the CdSe nanoparticles immobilized in the film were photoetched to smaller ones and their size was simply determined by the wavelength of irradiation light. Although almost no emission was observed in the original $\mathrm{SiO}_{2} / \mathrm{CdSe}$ (film), the photoetched films exhibited intense band gap emission, as seen for $\mathrm{SiO}_{2} /$ $\mathrm{CdSe}(\mathrm{col})$. The peak wavelength of the photoluminescence was blue-shifted with a decrease in the wavelength used for photoetching as shown in Figure 2b. In addition to the band gap emission, $\mathrm{SiO}_{2} / \mathrm{CdSe}$ (film) photoetched with 488 and 460 $\mathrm{nm}$ light exhibited broad emission around $560 \mathrm{~nm}$, which was attributed to the recombination of photogenerated charge carriers at surface defect sites. 
(a)

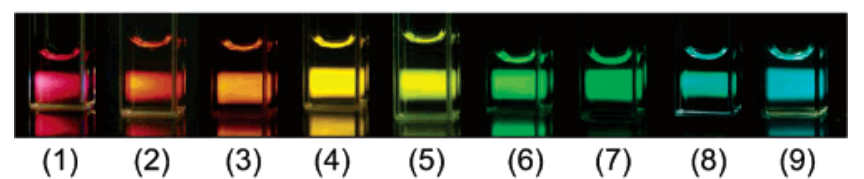

(b)

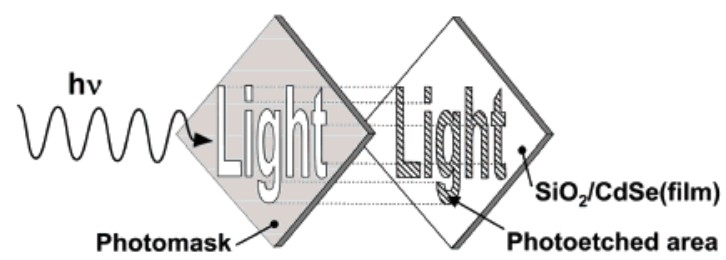

(c)

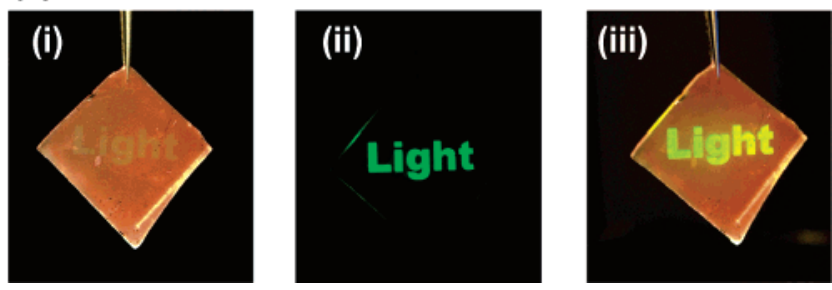

Figure 3. (a) Photographs of UV-illuminated $\mathrm{SiO}_{2} / \mathrm{CdSe}$ (col) solutions photoetched at 630 (1), 620 (2), 610 (3), 600 (4), 590 (5), 575 (6), 560 (7), $532(8)$, and $514 \mathrm{~nm}$ (9). The excitation wavelength was $350 \mathrm{~nm}$. (b) Schematic illustration of the patterned monochromatic irradiation on $\mathrm{SiO}_{2} / \mathrm{CdSe}$ (film). (c) Photographs of photoetched $\mathrm{SiO}_{2} / \mathrm{CdSe}$ (film) placed under room light (i), ultraviolet light $(350 \mathrm{~nm})$ (ii), and both lights (iii). Original CdSe particles were prepared at (a) 175 and (c) $150{ }^{\circ} \mathrm{C}$.

Figure 3a shows photographs of photoluminescent $\mathrm{SiO}_{2} / \mathrm{CdSe}$ (col) photoetched at various wavelengths. UV irradiation (350 $\mathrm{nm}$ ) induced band gap emission of photoetched CdSe nanoparticles in all of the solutions, and the color of photoluminescence was successively changed from red to blue with a decrease in the wavelength used for the photoetching. The quantum yields (QY) of photoluminescence were determined to be $0.003 \%$ (red), $1.1 \%$ (orange), $2.1 \%$ (green), and $1.8 \%$ (blue) for $\mathrm{CdSe}$ nanoparticles photoetched at $630,610,560$, and $514 \mathrm{~nm}$, respectively, while $\mathrm{SiO}_{2} / \mathrm{CdSe}$ before photoetching exhibited extremely weak photoluminescence with QY of ca. $10^{-5} \%$. Roughly speaking, these facts indicated that the photoetching of CdSe enhanced QY, with the degree being more remarkable with a shorter wavelength of light used for the size-selective photoetching, that is, with the formation of smaller CdSe particle, though the obtained QY was still lower than those reported for TOPO-modified CdSe $(5-15 \%) .{ }^{1}$ Since the photoetching made core particles with bare surfaces, ${ }^{27}$ it was suggested that the dangling bonds formed on the photoetched bare surfaces acted as the recombination sites.

Since original $\mathrm{SiO}_{2} / \mathrm{CdSe}$ exhibited almost no photoluminescence as mentioned above, it is expected that patterned monochromatic irradiation on CdSe nanoparticle films results in the formation of photoluminescence images. Figure $3 \mathrm{c}$ shows a photograph of a $\mathrm{SiO}_{2} / \mathrm{CdSe}$ (film) that was photoetched by irradiation at $560 \mathrm{~nm}$ through a photomask (Figure 3b). The red color of the original film was only slightly diminished in the irradiated area, though the written image was not clear under room light. On the other hand, UV irradiation $(350 \mathrm{~nm})$ induced intense green emission with the wavelength at $546 \mathrm{~nm}$ only in the photoetched area, resulting in the appearance of the clear green image "Light". The luminescence of the photoetched area

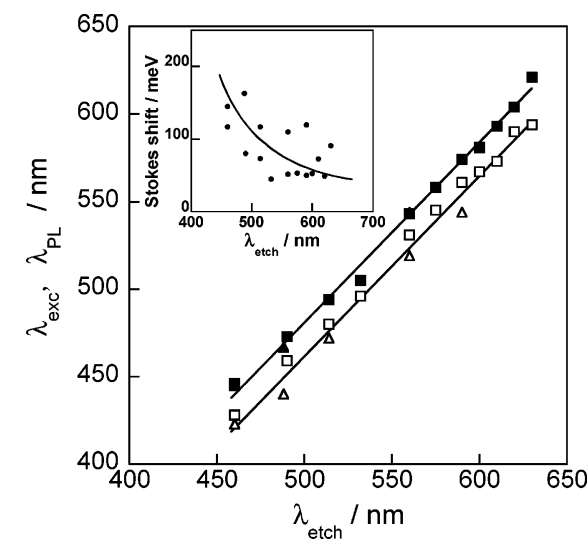

Figure 4. Dependence of $\lambda_{\text {exc }}$ (open symbols) and $\lambda_{\mathrm{PL}}$ (solid symbols) of photoetched CdSe nanoparticles on $\lambda_{\text {etch. }}$. Data were collected from the results for $\mathrm{SiO}_{2} / \mathrm{CdSe}$ (col) (squares) and $\mathrm{SiO}_{2} / \mathrm{CdSe}$ (film) (triangles), original $\mathrm{CdSe}$ particles of which having been prepared at 175 and $150{ }^{\circ} \mathrm{C}$, respectively. (Inset) Stokes shift of photoetched CdSe nanoparticles as a function of $\lambda_{\text {etch }}$.

under UV irradiation was intense enough to be seen under room light. The intensity of photoluminescence was almost constant when the photoetched film was stored under $\mathrm{Ar}$ atmosphere in the dark for at least 6 months.

Figure 4 shows the peak wavelength of the exciton absorption $\left(\lambda_{\text {exc }}\right)$ and the photoluminescence of photoetched CdSe nanoparticles $\left(\lambda_{\mathrm{PL}}\right)$ as a function of the wavelength of the irradiation light for size-selective photoetching $\left(\lambda_{\text {etch }}\right)$. Regardless of the kind of starting $\mathrm{SiO}_{2} / \mathrm{CdSe}, \lambda_{\text {exc }}$ linearly increased with an increase in $\lambda_{\text {etch }}$. The difference between $\lambda_{\text {exc }}$ and $\lambda_{\text {etch }}$ was roughly constant (ca. $40 \mathrm{~nm}$ ) at each $\lambda_{\text {etch. }}$. It has been reported ${ }^{31}$ that the broader size distribution caused the larger difference between the absorption onset and $\lambda_{\text {exc }}$. Since the absorption onset was in good agreement with $\lambda_{\text {etch }}$ as mentioned above, this fact suggested that the size distribution of photoetched $\mathrm{CdSe}$ nanoparticles was not greatly varied, regardless of $\lambda_{\text {etch }}$ used. Considering the reported relation between $\lambda_{\text {exc }}$ and the particle size, ${ }^{23}$ these results indicated that CdSe size could be controlled in the range $4.3-1.7 \mathrm{~nm}$ by changing $\lambda_{\text {etch }}$ in the range $630-$ $460 \mathrm{~nm}$. Furthermore, a linear relation between $\lambda_{\text {etch }}$ and $\lambda_{\mathrm{PL}}$ was also observed. The inset of Figure 4 shows the energy difference between $\lambda_{\mathrm{PL}}$ and $\lambda_{\mathrm{exc}}$ (i.e., Stokes shift) as a function of $\lambda_{\text {etch. }}$. Although plots were fairly scattered, it was clear that the Stokes shift tended to be enlarged with a decrease in $\lambda_{\text {etch }}$, that is, with decrease in the size of photoetched CdSe particles. A similar size dependence of Stokes shift has been reported by Bawendi and co-workers and theoretically explained by using the intrinsic exciton model, ${ }^{32}$ where the increase of Stokes shift was induced by the change in the energy structure of CdSe nanoparticles by decreasing their size. Thus, size-selective photoetching enabled fine-tuning of the band gap emission whose peak wavelength could be adjusted at the desired position by appropriate selection of the wavelength of irradiation light for the photoetching.

\section{Conclusion}

We have successfully controlled the photoluminescent properties of CdSe nanoparticles using the size-selective photoetching technique. The peak wavelength of photoluminescence could be postpreparatively adjusted by selection of the wavelength for the photoetching, and the luminescence color was tuned from red to blue. Such size-selective photoetching applied to $\mathrm{SiO}_{2} /$ CdSe films resulted in recovery of the band gap photoluminescence of $\mathrm{CdSe}$ nanoparticles that had disappeared in the 
preparation of the $\mathrm{SiO}_{2}$ shell layer and in the production of a clear photoluminescence image. Although only the image written by irradiation at $560 \mathrm{~nm}$ is described in this paper, this technique enables the production of a multicolored photoluminescence image by irradiation with monochromatic lights having various wavelengths using a single source material. By the combination of this technique and photolithography, semiconductor nanoparticles having desired optical properties can be produced in the required position of nanoparticulate films. This will be useful for the application of luminescent semiconductor nanoparticles to electronic and optical devices. Study along this line is currently in progress.

Acknowledgment. This research was partially supported by a Grant-in-Aid for Scientific Research (B) (no. 16350095) from the Japan Society for the Promotion of Science and by a Grantin-Aid for Scientific Research on Priority Areas (417) from the Ministry of Education, Culture, Sports, Science and Technology (MEXT) of Japan. T.T. thanks the Hosokawa Powder Technology Foundation for financial support.

Supporting Information Available: The schematic illustration of the preparation of $\mathrm{SiO}_{2} / \mathrm{CdSe}$ (col) and $\mathrm{SiO}_{2} / \mathrm{CdSe}$ (film), and the figure showing the normalized PL spectra of $\mathrm{SiO}_{2} / \mathrm{CdSe}$ (col) nanoparticles during size-selective photoetching at $560 \mathrm{~nm}$. This material is available free of charge via the Internet at http:// pubs.acs.org.

\section{References and Notes}

(1) Dabbousi, B. O.; Rodriguez Viejo, J.; Mikulec, F. V.; Heine, J. R.; Mattoussi, H.; Ober, R.; Jensen, K. F.; Bawendi, M. G. J. Phys. Chem. $B$ 1997, 101, 9463-9475.

(2) Murray, C. B.; Kagan, C. R.; Bawendi, M. G. Annu. Rev. Mater. Sci. 2000, 30, 545-610.

(3) Mulvaney, P.; Liz-Marzan, L. M.; Giersig, M.; Ung, T. J. Mater. Chem. 2000, 10, 1259-1270.

(4) Aldana, J.; Wang, Y. A.; Peng, X. G. J. Am. Chem. Soc. 2001, $123,8844-8850$

(5) Gerion, D.; Pinaud, F.; Williams, S. C.; Parak, W. J.; Zanchet, D.; Weiss, S.; Alivisatos, A. P. J. Phys. Chem. B 2001, 105, 8861-8871.

(6) Talapin, D. V.; Rogach, A. L.; Shevchenko, E. V.; Kornowski, A.; Haase, M.; Weller, H. J. Am. Chem. Soc. 2002, 124, 5782-5790.

(7) Nosaka, Y.; Tanaka, H. J. Phys. Chem. B 2002, 106, 3389-3393.

(8) Alivisatos, A. P.; Gu, W. W.; Larabell, C. Annu. Rev. Biomed. Eng. 2005, 7, 55-76.
(9) Robel, I.; Subramanian, V.; Kuno, M.; Kamat, P. V. J. Am. Chem. Soc. 2006, 128, 2385-2393.

(10) Burda, C.; Chen, X. B.; Narayanan, R.; El-Sayed, M. A. Chem Rev. 2005, 105, 1025-1102.

(11) Jasieniak, J.; Bullen, C.; van Embden, J.; Mulvaney, P. J. Phys Chem. B 2005, 109, 20665-20668.

(12) Teranishi, T.; Nishida, M.; Kanehara, M. Chem. Lett. 2005, 34, 1004-1005

(13) Torimoto, T.; Nishiyama, H.; Sakata, T.; Mori, H.; Yoneyama, H. J. Electrochem. Soc. 1998, 145, 1964-1968.

(14) Torimoto, T.; Kontani, H.; Shibutani, Y.; Kuwabata, S.; Sakata, T.; Mori, H.; Yoneyama, H. J. Phys. Chem. B 2001, 105, 6838-6845.

(15) Torimoto, T.; Reyes, J. P.; Iwasaki, K.; Pal, B.; Shibayama, T.; Sugawara, K.; Takahashi, H.; Ohtani, B. J. Am. Chem. Soc. 2003, 125, 316-317.

(16) Pal, B.; Torimoto, T.; Iwasaki, K.; Shibayama, T.; Takahashi, H.; Ohtani, B. J. Phys. Chem. B 2004, 108, 18670-18674.

(17) Kuwabata, S.; Ueda-Sarson, K.; Torimoto, T. Chem. Lett. 2004, $33,1344-1345$

(18) van Sark, W.; Frederix, P.; van den Heuvel, D. J.; Gerritsen, H. C.; Bol, A. A.; van Lingen, J. N. J.; Donega, C. D.; Meijerink, A. J. Phys. Chem. B 2001, 105, 8281-8284.

(19) Cordero, S. R.; Carson, P. J.; Estabrook, R. A.; Strouse, G. F.; Buratto, S. K. J. Phys. Chem. B 2000, 104, 12137-12142.

(20) Jones, M.; Nedeljkovic, J.; Ellingson, R. J.; Nozik, A. J.; Rumbles, G. J. Phys. Chem. B 2003, 107, 11346-11352.

(21) Guo, W. H.; Li, J. J.; Wang, Y. A.; Peng, X. G. J. Am. Chem. Soc. 2003, 125, 3901-3909

(22) Wang, Y.; Tang, Z. Y.; Correa-Duarte, M. A.; Liz-Marzan, L. M.; Kotov, N. A. J. Am. Chem. Soc. 2003, 125, 2830-2831.

(23) Yu, W. W.; Qu, L. H.; Guo, W. Z.; Peng, X. G. Chem. Mater. 2003, 15, 2854-2860.

(24) Katari, J. E. B.; Colvin, V. L.; Alivisatos, A. P. J. Phys. Chem. 1994, 98, 4109-4117.

(25) Derfus, A. M.; Chan, W. C. W.; Bhatia, S. N. Nano Lett. 2004, 4, $11-18$.

(26) Wang, Y.; Tang, Z. Y.; Correa-Duarte, M. A.; Pastoriza-Santos, I.; Giersig, M.; Kotov, N. A.; Liz-Marzan, L. M. J. Phys. Chem. B 2004 $108,15461-15469$.

(27) Iwasaki, K.; Torimoto, T.; Shibayama, T.; Takahashi, H.; Ohtani, B. J. Phys. Chem. B 2004, 108, 11946-11952.

(28) Talapin, D. V.; Rogach, A. L.; Mekis, I.; Haubold, S.; Kornowski, A.; Haase, M.; Weller, H. Colloids Surf., A 2002, 202, 145-154.

(29) Bullen, C.; Mulvaney, P. Langmuir 2006, 22, 3007-3013.

(30) Qu, L. H.; Peng, Z. A.; Peng, X. G. Nano Lett. 2001, 1, 333-337.

(31) Weller, H.; Schmidt, H. M.; Koch, U.; Fojtik, A.; Baral, S.; Henglein, A.; Kunath, W.; Weiss, K.; Dieman, E. Chem. Phys. Lett. 1986 $124,557-560$.

(32) Kuno, M.; Lee, J. K.; Dabbousi, B. O.; Mikulec, F. V.; Bawendi, M. G. J. Chem. Phys. 1997, 106, 9869-9882. 